\title{
The Crossovers and Connectivity between Systems Engineering and the Sustainable Development Goals: A Scoping Study
}

\author{
Lan Yang ${ }^{1, *(\mathbb{D})}$ and Kathryn Cormican ${ }^{1,2}$ (D) \\ 1 School of Engineering, College of Science and Engineering, National University of Ireland, Galway, \\ H91 TK33 Galway, Ireland; kathryn.cormican@nuigalway.ie \\ 2 Lero-The Irish Software Research Centre, School of Engineering, National University of Ireland, Galway, \\ H91 TK33 Galway, Ireland \\ * Correspondence: lan.yang@nuigalway.ie
}

check for updates

Citation: Yang, L.; Cormican, K. The Crossovers and Connectivity between Systems Engineering and the Sustainable Development Goals: A Scoping Study. Sustainability 2021, 13, 3176. https://doi.org/10.3390/su 13063176

Academic Editor: Cecilia Haskins

Received: 26 January 2021

Accepted: 11 March 2021

Published: 14 March 2021

Publisher's Note: MDPI stays neutral with regard to jurisdictional claims in published maps and institutional affiliations.

Copyright: (c) 2021 by the authors. Licensee MDPI, Basel, Switzerland. This article is an open access article distributed under the terms and conditions of the Creative Commons Attribution (CC BY) license (https:/ / creativecommons.org/licenses/by/ $4.0 /)$.

\begin{abstract}
The United Nation's sustainable development goals (SDGs) are interconnected and indivisible and need to be addressed in a systematic and holistic way. However, a lack of stakeholder perspective, fragmented responses, and a dearth of integration across sectors have long been perceived as the SDGs' main pitfalls. In recent years, scholars are calling to address these issues by adopting a systems engineering perspective, as this approach espouses a stakeholder-focused position, embraces a holistic and dynamic mindset, and provides a variety of technical and managerial toolkits, which can help to untangle the complexity and interactions inherent in global sustainability. Nevertheless, little has been done to map the existing literature, comprehensively review, and synthesize research evidence in this field. Therefore, this paper aims to conduct a scoping study that analyzes the extant evidence to uncover the contributions of systems engineering in advancing the SDGs. A three-phase methodology integrating natural language processing and systematic literature review is used to investigate this space. We conclude that systems engineering has been an active catalyst promoting the SDGs, and that systems engineering has the potential to support more transdisciplinary research to achieve long-term transformational and sustainable change across sectors and disciplines.
\end{abstract}

Keywords: sustainable development goals; systems engineering; systems thinking; complex adaptive systems; socio-technical systems; system of systems; cyber physical systems; natural language processing

\section{Introduction}

Sustainable development has become an underlying strategy to guide global transformation [1]. The goal of sustainable development has evolved from pursuing the single goal of sustainable use of natural resources to resolving the complexities of economic development, environmental protection, and societal polarization [2]. In September 2000, the United Nations (UN) Millennium Summit published the Millennium Development Goals (MDGs) comprising 8 key areas and 21 operational goals [3]. These goals guided national development and international cooperation for the first 15 years in the new century. In 2012, the UN Conference on Sustainable Development in Rio de Janeiro called for a revision of the MDGs [4]. On 25 September 2015, the General Assembly of the UN adopted a resolution "Transforming our world: the 2030 Agenda for Sustainable Development" [5]. The agenda announced 17 sustainable development goals (SDGs) and 169 specific targets. They replaced the MDGs and strive to shift the world onto a more sustainable path.

Since the SDGs were announced, scholars have invested considerable effort in identifying new sustainable solutions to face the complex and interwoven challenges. The key is to take an integrated and balanced consideration of the three dimensions relating to sustainable development: economic, social, and environmental. Barbier and Burgess [6] were among the first to advocate using a systems approach to characterize sustainability 
in terms of the optimization of goals across social, economic, and environmental systems through an adaptive process of trade-offs.

According to the agenda, the 17 SDGs should be viewed in an integrated manner and cannot be separated from each other [5]. However, in reality, the SDGs are very broad and diverse. They are overly fragmented in their formulation and largely sectoral [7]. In other words, there is a lack of integration across sectors in terms of strategies, policies and implementation. Little guidance has been given on how to trade off and balance the goals [6]. In addition, the SDGs have been criticized for lacking stakeholder perspectives and being ambiguous about their target audience [8]. Furthermore, Laurent et al. [9] advocated that more attention should focus on the method and approach to achieve these goals. Therefore, the achievement of the SDGs needs a holistic and systematic approach. The dynamics and complexity of the SDGs should be considered when prioritizing and optimizing the goals [10]. It is clear that there is an urgent need for a holistic and systematic perspective when seeking a feasible solution to harmonizing the SDGs [11,12].

However, addressing sustainability in such a wide range of contexts can be highly complex. This diversity suggests a need for a systematic and multidisciplinary approach to help tackle these problems. Systems engineering is a suitable methodology to help with this. Systems engineering [13] is an integrative and transdisciplinary approach that focuses on establishing, balancing and integrating stakeholders' requirements. It also focuses on the entire life cycle process to achieve goals, considering the levels of uncertainty, variety, change, and complexity. Systems thinking [14] is at the heart of systems engineering, as it considers the interconnections, dynamics and emergent behavior of system components. In other words, it can focus on the patterns of change rather than a static 'snapshot' of the current problem. In addition, the systems approach advocates and follows a system life cycle process, which can identify potential risks at the earliest stakeholder requirement definition and system conceptualization stage. This can help recognize ecologically or socially problematic decisions and manage the sustainability impacts throughout the entire life cycle of a process, product, or service.

Although systems engineering has many functions and benefits, there is a dearth of research that analyzes the connectivity between systems engineering and the SDGs. For example, little is known about where systems engineering has been used to advance the SDGs, and what systems engineering knowledge has been used in previous studies.

In order to address these deficits, our paper presents a scoping study that identifies existing synergies between systems engineering and the SDGs and helps build a foundation for future research directions. Whereas there are various methodological approaches for scoping studies [15], we focused on the most cited ones [16-18] and tailored them to our needs. Furthermore, we integrated natural language processing (NLP) [19] and systematic literature review (SLR) [20] in the process to pursue and ensure a rigorous and transparent method for synthesis and analysis. We adopted a three-phase analytical approach, namely (1) data collection and pre-processing, (2) data visualization and analysis, and (3) results interpretation. NLP is used in the first two phases and the principles of the SLR guides us throughout the study.

This research identifies the relevant literature and analyzes and interprets the crossovers and synergies between systems engineering and the SDGs. The results identify specific areas in which sustainable development can apply systems engineering knowledge to obtain sustained competitive advantage while attempting to address the sustainability expectations of the SDGs.

\section{Materials and Methods}

The research methodology involves three phases. As shown by the schematic figure (Figure 1), they are: Phase I, data collection and pre-processing, Phase II, data visualization and analysis, and Phase III, results interpretation. The following subsections further explain each phase. 


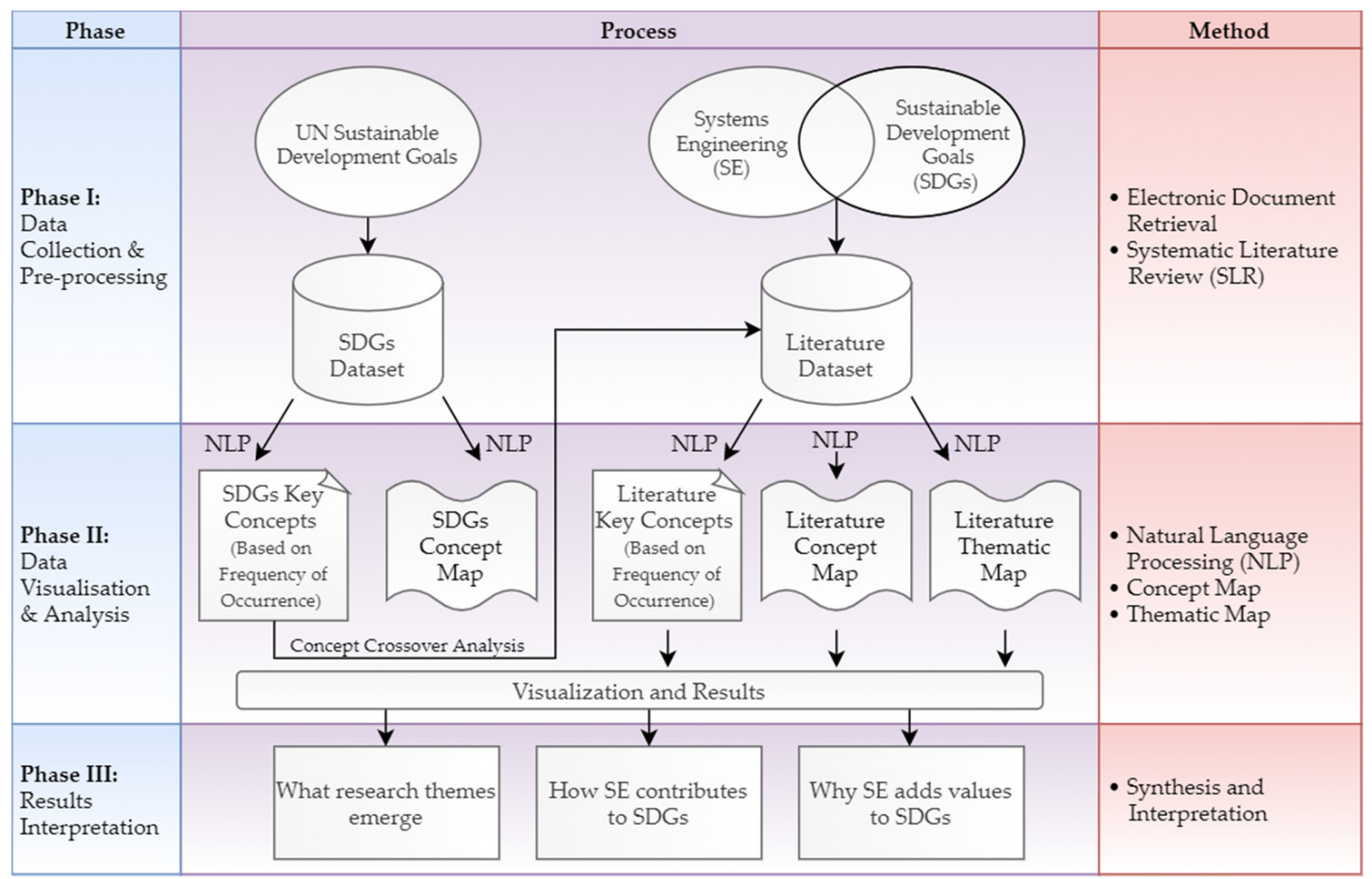

Figure 1. Research process.

\subsection{Phase I: Data Collection and Pre-Processing}

The first phase of the study involves assembling an SDGs dataset and a literature dataset. The SDGs dataset is made up of the 17 goals and their 169 targets and was obtained from the UN Sustainable Development Goals website. The literature dataset is composed of a group of scientific papers that uses systems engineering to advance the SDGs. We used SLR techniques to attain this scientific paper dataset. More specifically, we designed our search strings to retrieve papers that apply systems engineering core concepts to the context of sustainable development. The search query ensures that it returns any document whose title, abstract or keyword contains at least one term related to systems engineering and at least one term related to sustainable development. The search terms are listed in Table 1. We repeated the same query in many leading databases to ensure an adequate coverage, including Scopus, Web of Science, ProQuest, Science Direct, and IGI Global, and then we removed any duplicates.

Table 1. Search terms.

\section{Search Terms Related to Systems} Engineering

Search Terms Related to SDGs

systems engineering, systems thinking,

systems theory, systems science, systems approach, systems modelling, systems life cycle, systems analysis, system of systems, complex systems, complex adaptive systems,

sustainable development, sustain, sustainment, sustainability, SDGs cyber-physical systems, sociotechnical systems, systems engineer

The review was completed progressively over several weeks. To ensure their relevance and to confirm that each paper aligned well with our study, papers were carefully reviewed. 
The results were filtered to include only peer-reviewed, English-language academic articles for which full-text papers were available. A dataset of 45 unique papers resulted in this.

\subsection{Phase II: Data Visulization and Analysis}

The second phase involved an application of an emerging method in artificial intelligent called natural language processing (NLP). This method is proven to be useful in concept extraction, topic modeling, and content categorization to explore large datasets and has been employed by a diverse range of users. We used it to iteratively build up a map of associated concepts to analyze the concept crossovers and themes within the topic area. To apply this method, we used a text processing tool called Natural Language Toolkit (NLTK). NLTK is one of the most powerful NLP libraries which contains packages to parse text datasets. The approach taken is as follows.

First, we defined the key concepts. Here, a concept comprises a collection of terms that describe the same thing and often travel together throughout the text. To determine whether a term is related to a concept, it was weighted according to how frequently it occurs in a sentence that contains the concept, compared to how frequently it occurs elsewhere. The occurrence of each word in a phrase makes an adequate contribution to the cumulative evidence for the presence of a concept, since terms are weighted. To eliminate duplicates, group similar terms, remove incorrectly defined terms, and maintain a stable collection of outcomes, the resulting concepts were manually vetted. Next, we created themes which comprise a cluster of interconnected concepts. Though clustering, a thematic view of relationships between concepts was generated. In other words, we used NLTK to interpret document sets and built maps of key concepts, where their relationships are suggested by their connectedness or distance on the map. Qualitative analyses can be carried out on the basis of quantitative, algorithmic analysis by analyzing the resulting concept map, frequency distributions, and relationships between both concepts and themes. NLP was used to detect the main concepts present in the datasets (according to their frequency of occurrence), cluster these concepts, and consequently uncover the relationships between them.

There are two datasets involved in the study, i.e., the SDGs dataset and the literature dataset. As shown by Figure 1, they are both analyzed using NLP.

The NLTK processed a digital copy of the SDGs and associated targets. To obtain a frequency distribution of the concepts, the full text of the 17 objectives and the corresponding 169 target specifications were processed over several iterations. For clarification, terms inappropriately defined as concepts (e.g., 'including', 'particular', 'inclusive') were discarded manually from the study. As a result, we generated a list of key concepts that contain the core information with their frequency of occurrence in the SDGs text. We then developed a concept map that demonstrate how these concepts are thematically linked.

Regarding the literature dataset, the full texts of the 45 papers were analyzed from four dimensions. First, we used the key concepts generated from the SDGs dataset as seed concepts and applied them to the literature dataset to examine how these concepts are addressed and covered by the literature. This approach allowed us to evaluate the concept crossovers and connectivity between the SDGs and the literature. Next, the literature dataset was analyzed through NLP and resulted in a frequency distribution of the key concepts within the literature and a concept map. We then compared the outcomes with the concept map of the SDGs dataset to distinguish the similarity and differences. Finally, to gain a better understanding of the themes covered by the literature, we developed a thematic map. Together with the analysis above, the thematic map was used to identify research trends, as well as to interpret research gaps.

This phase was not intended to investigate specific cases of how systems engineering is applied to advance SDGs, but to establish the concept crossovers between the SDGs and the extant research performed via systems engineering perspectives. 


\subsection{Phase III: Results Interpretation}

The third phase produced a detailed and extensive interpretation of the integrated results from the NLP analysis as well as from the literature review. Our goal was to provide insights on the following three aspects, i.e., what research themes emerged from the literature, how systems engineering supports the implementation of the SDGs, and why systems engineering can add value to the SDGs. By analyzing the above questions, we investigated where systems engineering and the SDGs overlap, and consequently determine the crossovers and connectivity between them.

\section{Results}

\subsection{Results from Phase I}

A total of 45 academic articles that focus on systems engineering and the SDGs were identified through the search and initial review, including 35 journal articles, 6 conference papers, and 4 book chapters. Publication per year generally followed an upward trend (as shown in Figure 2), with only 1 paper published in 2009, 2012, 2015, and 2016, respectively, 5 papers in 2017, 13 papers in 2018, and 15 papers in 2019. Since this time, the numbers have decreased marginally, with 8 published in 2020.

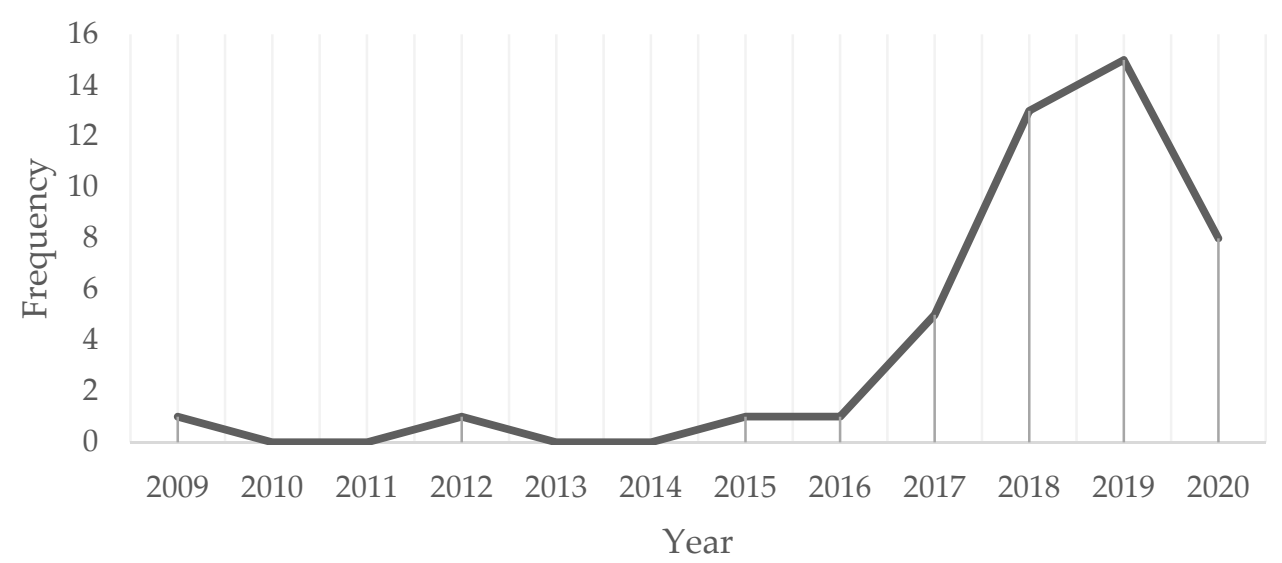

Figure 2. Trend of the publications over the timeframe 2009-2020.

The journals in this area are written in the fields of environmental science, social science, energy, engineering, public health, earth and planetary science, chemistry, sociology and political science, education, and ecology. The literature focuses on the use of systems thinking, systems approach, and integrated tools to implement the SDGs, spanning the three pillars (environmental, social and economic) of sustainable development. Major application areas include information, energy, production, health, technology, climate, and policy.

\subsection{Results from Phase II}

\subsubsection{NLP Analysis for the SDGs}

Figure 3 shows the stable concept map that depicts the relationships between the concepts generated from the SDGs dataset through NLP. The results provide 38 key concepts that characterize the SDGs and later become the seed concepts that are used to analyze the crossovers with the literature dataset.

In Figure 3, the size of the dots represents the frequency of occurrence (the larger the dots, the higher the frequency). The length of the lines linking the dots represent the co-occurrence of two concepts in the corpus (the shorter the distance, the more often they co-occur in a sentence). As the generation of the concept map is based on how often two concepts travel together in the SDGs text and how closely they are to each other, we can use the concept map to present whether two concepts are mentioned together repeatedly 
in the same context. As a result, several clusters were constructed represented by the same color in Figure 3, where the concepts gather and become a theme.

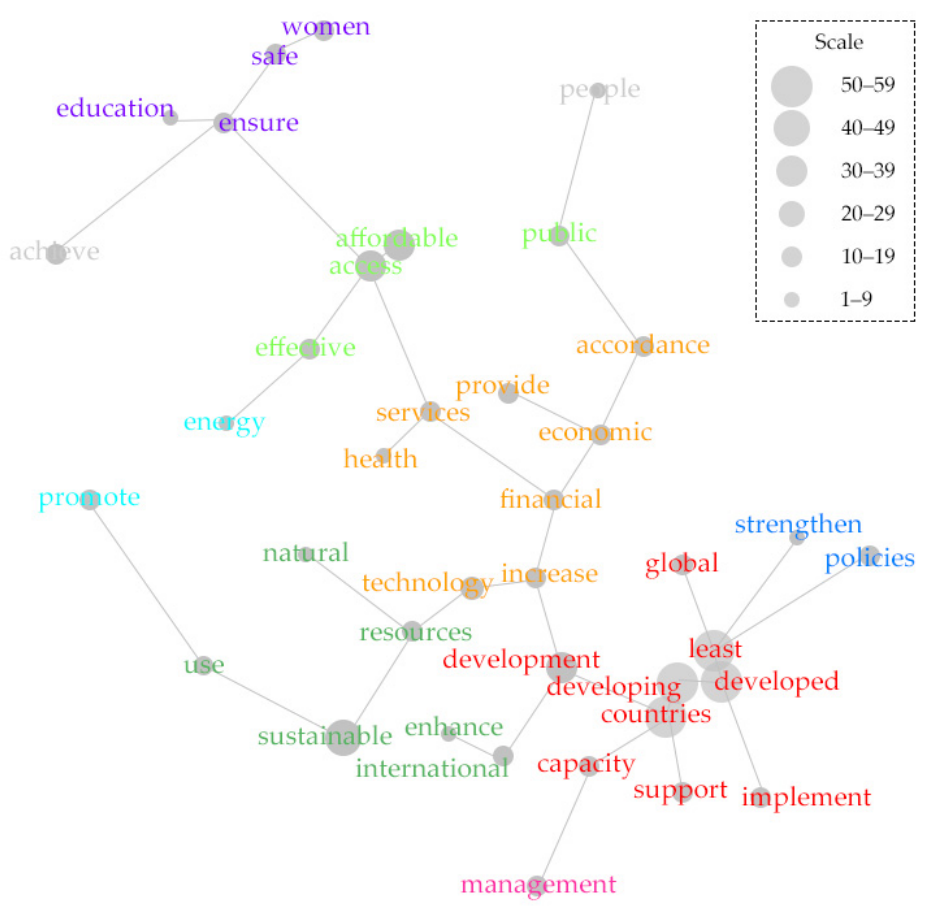

Figure 3. Concept map with clusters derived from natural language processing (NLP) analysis of the sustainable development goals (SDGs).

Major collocations that emerge from the NLP analysis are 'least developed' and 'development countries', which is unsurprising given the context in which they were released. Both are at the center of the red cluster. We found 'capacity' and 'support' are close to 'developing countries', while 'development' is at the boundary of the red cluster, linking the yellow cluster as well. The second largest dot is 'sustainable', which appears in the green cluster. This cluster is related to the sustainable use of ecosystems and resources (key concepts including 'energy', 'resources', 'sustainable', 'natural', and 'technology'). The green and the red clusters are located closely next to each other, indicating that they have concepts that overlap between the two, such as 'resources', 'enhance' and 'international'. The green and the yellow clusters share a fuzzy boundary, where 'resources' and 'technology' links with each other. The rest of the clusters are relatively far away from the main body, but they form several distinct themes. For example, there is a separate theme that stands out. This is colored in purple. It emphasizes the importance of the safety of women and the assurance of education and access to needs for women ('women', 'safe', 'education', 'access' and 'affordable'). We found 'affordable access' is frequently mentioned. It is in the middle of the purple cluster and the yellow cluster, linked with the purple cluster by 'ensure' and with the yellow cluster by 'services'. In addition, 'services' is connected with 'health' closely. Based on these observations, we infer that the SDGs emphasize an affordable access to health-related services.

However, in the stable concept map, 'management' is often located on the outside (in pink), with few connections, suggesting that this idea is not addressed to any great degree in the text of SDGs.

\subsubsection{NLP Analysis for the Literature}

We conducted two types of NLP analysis on the literature dataset. The first analyzed the concept crossovers and connections between the literature and the SDGs. In other words, we used the 38 concepts as seed concepts and analyzed how frequently they are discussed in the 45 papers. The second analysis was conducted only on the literature 
dataset itself and was done to identify the key concepts and themes of the 45 papers. From the first analysis, the concepts identified from the SDGs (as seed concepts) and also shown in the literature dataset, along with their frequency counts and relevance scores are shown in Table 2. Figures 4 and 5 are the concept map and thematic map developed from the literature dataset, respectively.

Table 2. Concept crossovers and connectivity between the SDGs and the literature.

\begin{tabular}{cccccc}
\hline Concept & Count & Relevance $\%$ & Concept & Count & Relevance \% \\
\hline energy & 1128 & 100 & natural & 289 & 26 \\
development & 1095 & 97 & services & 283 & 25 \\
sustainable & 1071 & 95 & developing & 246 & 22 \\
use & 939 & 83 & capacity & 241 & 21 \\
management & 625 & 55 & policies & 217 & 19 \\
health & 581 & 52 & achieve & 200 & 18 \\
economic & 578 & 51 & international & 176 & 16 \\
global & 568 & 50 & effective & 165 & 15 \\
countries & 438 & 39 & women & 150 & 13 \\
access & 424 & 38 & ensure & 140 & 12 \\
people & 407 & 36 & financial & 127 & 11 \\
technology & 404 & 36 & promote & 117 & 10 \\
resources & 401 & 36 & least & 117 & 10 \\
provide & 359 & 32 & safe & 103 & 9 \\
education & 352 & 31 & enhance & 82 & 7 \\
public & 345 & 31 & affordable & 80 & 7 \\
support & 341 & 30 & implement & 61 & 5 \\
developed & 308 & 27 & accordance & 16 & 1 \\
increase & 293 & 26 & strengthen & 14 & 1 \\
\hline
\end{tabular}

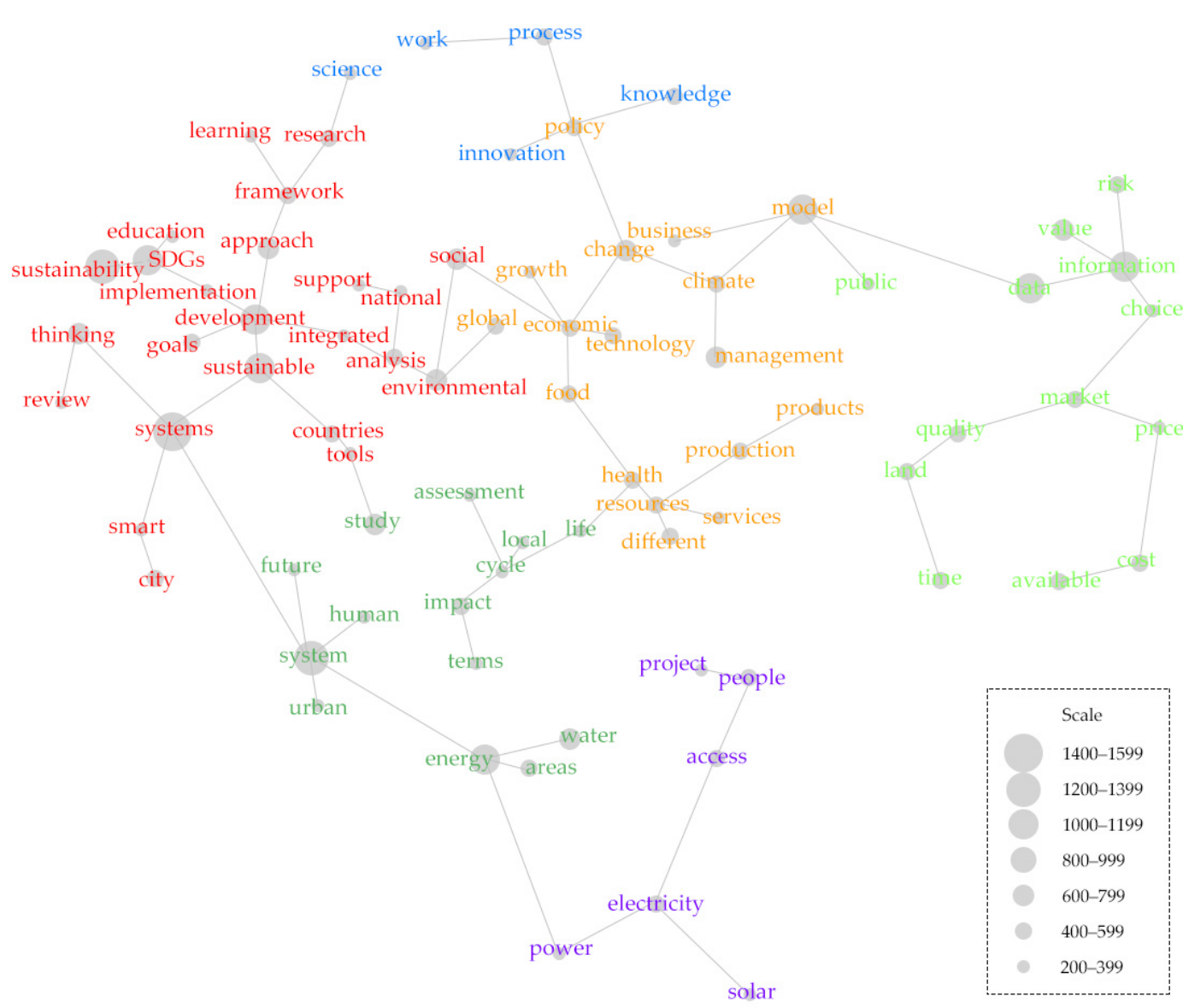

Figure 4. Concept map with clusters derived from NLP analysis of the literature. 
From Table 2, we found that of the 38 concepts identified as key in the analysis of the SDGs (concepts in Figure 3), all 38 are directly identified as having some degree of relevance in the literature dataset. This relevance varies from 'energy' at 100\% and 1128 mentions in the literature dataset, to 'strengthen', which receives only 14 mentions and has a relevance score of $1 \%$. The crossovers between the SDGs and the literature in the field of systems engineering and sustainable development are representative of the fact that all concepts appear in the literature dataset.

Figure 4 shows the concept map of the 45 papers, with the key concepts highlighted in large dots and the clusters forming several different topic groups. The literature focuses on key concepts including 'systems', 'sustainability', 'model', 'data', 'energy', 'SDGs', 'information', and their interaction with 'sustainable development', along with 'social', 'economic' and 'environmental' factors. These concepts are further grouped into themes based on their relationships in a concept map, as shown by Figure 5 .

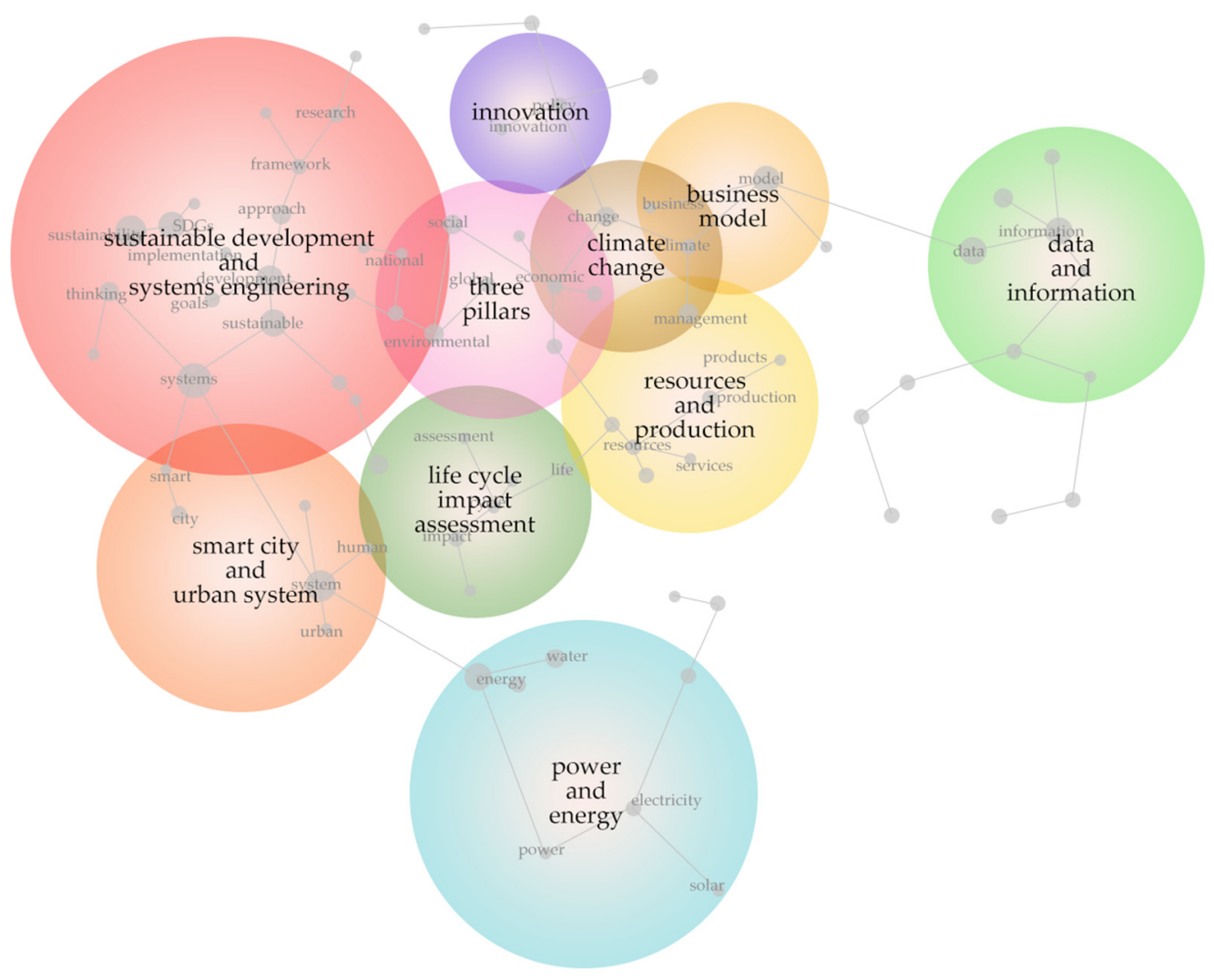

Figure 5. Thematic map derived from NLP analysis of the literature.

Comparing Figure 4 with Figure 3, we found that Figure 4 contains many identical concepts that appeared in the SDGs but also include many other concepts that are relative to systems engineering. Moreover, in Figure 4, the clustering is more obvious. The core concepts of the red cluster and the yellow cluster are relevant to systems engineering and sustainability. The three pillars of the SDGs (social, environmental and economic) are on the boundary. What is interesting is that the concepts 'environmental' and 'social' are closer to the red cluster, whereas 'economic' is close to 'food', 'growth' and 'change'. The blue cluster is more about 'innovation', 'process' and 'knowledge', with 'policy' acting as a glue to hold them together. There is a special focus on 'information' and 'data' in the literature, which stands out alone (the lime green cluster). To better illustrate the themes, we developed a thematic map shown by Figure 5 .

In Figure 5, we found that the literature contains several themes, such as sustainable development and systems engineering (including systems thinking, approach, framework, etc.), smart city and urban system, life cycle impact assessment, climate change, business 
model, research that is relevant to the three pillars, innovation, resources and production, power and energy, as well as data and information. The results obtained from the NLP analysis of the literature help us to understand the general research foci and trends. They offer a bird-eye view of the extant literature that focuses on using systems engineering to advance sustainable development.

\subsection{Results from Phase III}

In the third phase of the analysis, we conducted an in-depth analysis of the 45 papers. They are categorized by their theoretical foundations in relation to systems engineering, such as systems thinking, socio-technical systems, complex adaptive systems, system of systems, etc. For each domain, we analyzed the definitions of the key concept related to systems engineering especially for the context of sustainable development research. We are particularly interested in what research themes have emerged from the literature, how systems engineering supports the implementation of the SDGs, and how systems engineering can add value to the SDGs.

\subsubsection{Systems Engineering}

By definition, systems engineering is a transdisciplinary and integrative approach to enable the successful realization, use, and retirement of engineered systems, using systems principles and concepts, and scientific, technological, and management methods [13]. In the overall life cycle context, systems engineering deals with the analysis and design, operation and maintenance of large interconnected systems and helps to maintain the scale and constraints of a multidisciplinary research problem [21]. In the study of sustainable development, systems engineering is seen as a provider of knowledge principles and practices that better facilitate the integration of economic, environmental and social efficiency and effectiveness in achieving sustainable development [22]. It provides the holistic perspective needed to guide the analysis, design, implementation, integration and maintenance of complex systems composed of different interrelated components interacting together to reach a specific goal [23].

System engineering is important to sustainable development mainly due to the following three aspects.

First, model-based systems engineering enables the design of complex systems, especially for large systems that support sustainability [24-26]. For example, building the architecture of large earth observation systems heavily relies on successful systems modelling [27]. These systems are essential to analyze natural environment changes, predict the impact of the changes on humans, and offer a decision-making support in response to the environmental changes. Model-based systems engineering plays a role in ensuring the design and implementation of such systems.

Second, systems engineering has the potential to significantly contribute to the evaluation of socio-technical systems [28-30]. For instance, Palmer et al. [31] used systems engineering to develop a framework for a systematic and systemic mapping of bioeconomic transitions within and between socio-technical systems. The conceptualization of bioeconomy transitions naturally leads itself towards systems engineering, as systems engineering offers a socio-technical perspective.

Third, systems engineering can assist decision-makers to implement the SDGs in an improved, consistent, traceable, and transparent manner. Deshpande and Aspen [21] provide a systems engineering framework to make SDGs more practical. This stepwise framework, embedded in system engineering, uses models to help create clear, traceable, and transparent connections between SDGs, targets, strategies for change and decisions.

These three points prove the positive impact that system engineering has on the SDGs. Next, we analyze in detail how the core concepts of systems engineering are applied in sustainable development research. 


\subsubsection{Systems Thinking}

Systems thinking has been interpreted in numerous ways. The core features include a recognition of interrelationships and the use of holistic approaches [32,33], an investigation of dynamic and emergent behavior arising from feedback [34], and a focus on patterns of change rather than static 'snapshots' [35]. Systems thinking is founded on the conviction that parts of the system will behave differently when viewed in isolation [36].

According to our analysis, systems thinking contributes to the realization of the SDGs in two ways. First, understanding the critical linkages among the SDGs requires systems thinking $[37,38]$. Second, systems thinking is applied to solve specific problems that contribute to the implementation of one or some SDGs [39-41].

Regarding the first point, many researchers have discussed the importance of systems thinking in analyzing SDGs. Allen et al. [38] endorsed the use of systems thinking to define and evaluate interlinkages among the SDGs and examine synergies and trade-offs to promote the formulation of visions, plans and strategies. As the SDGs framework gains momentum, all 17 goals and their interrelationships should be taken into consideration [42]. Additionally, as the SDGs cannot be approached in a linear and deterministic way, it is important to consider the dynamic condition that is inherent in the SDGs. Systems thinking provides a greater understanding of how the dynamics exist by exploring the relations and changes within the system [43]. In addition, the application of the SDGs explicitly calls for an integrated, comprehensive, multi-stakeholder solution to be created [44]. This signifies the need for systems thinking in practice to enhance better conversations and cooperation globally.

Regarding the second point, many studies have shown that pivoting from unsustainable to sustainable in a particular space requires systems thinking. While these studies come from several application areas, special attention has been paid to integrating systems thinking into education. For example, many researchers have agreed and proved that incorporating systems thinking into the chemistry curriculum can equip the next generation with the skills required to produce more sustainable and cleaner technologies, bringing the planet closer towards a sustainable society $[34,40,45]$. A systems thinking mindset is also crucial to engineers because a sustainable engineering system will not only require engineers have analytical skills, creativity, and a wide breadth of education but also take into account the multiple impacts on the natural, economic and social environment [46,47]. Therefore, the promotion of systems thinking in engineering education is crucial for equipping engineers with a sense of sustainability. Eustachio et al. [48] believed the key is to relate the complexity of sustainability to educational learning outcomes. It is system thinking that offers tools for complexity management by moving problem frameworks from linear explanations of cause-effects to an understanding of the broader context in which interventions may occur. Reynolds et al. [44] discussed the role of systems thinking in practice for supporting SDGs implementation capability. Kioupi and Voulvoulis [49] developed a framework that enables stakeholders in education to create a shared vision of sustainability, with the SDGs as endpoints. Systems thinking is used as a methodology to look at the overall picture of the importance of education in facilitating such transformation. A systems thinking approach has also been used in other studies to optimize the sustainable use of the system, such as scaling-up local measures for better medical care [32], scaling-up food production [50], growing sustainable aquaculture [36], understand the impact of land management [51], smart and sustainable city [43]. Although these endeavors happened in different domains, systems thinking offers opportunities for improving knowledge exchange through wider engagement.

\subsubsection{System Theory, Systems Analysis, System Dynamics, and Systems Modeling}

Systems theory has a long history and is inseparable from systems science and systems thinking. General system theory [52] discusses the holism and wholeness of a system, the need for integration of knowledge, open and closed systems, feedback loops, interactions between elements of the system, and emergence. Systems theory is closely related to 
cybernetics. Now, system theory has spread and evolved to other fields such as business, management and biodiversity [53]. System theory has also been used to better understand social systems and predict behavior [54]. It is beneficial to the SDGs because it helps to develop a holistic viewpoint when developing a new framework for sustainable development, enabling traceability of stakeholder requirements and equality of stakeholders from all over the world [55]. Consequently, the SDGs can be viewed in a systemic way, reducing complexity for governments, scholars and civil society engaged in the process of expanding awareness to take steps towards a more sustainable system.

Systems science is broken down into systems theory, systems analysis and cybernetics [56]. The perspectives gained from systems theory and cybernetics contributes to various interdisciplinary approaches. Especially notable is the approach called system dynamics, which is used to help explain nonlinear behavior in complex systems. It is a systems analysis approach that is used to research behavioral patterns of systems. Obersteiner et al. [57] proposed a design methodology focused on the dynamics of systems to determine the effects of earth observation systems, which have tremendous potential to help ensure the planet's sustainable future. Systems analysis is an evolving tool for the evaluation of interlinkages between SDGs that can be used to help the prioritization of targets [58]. The application of systems analysis leads to more equitable, more resilient and more sustainable assistive technology [35].

Ideally, a sustainability evaluation should incorporate the assessment of a consequence caused by a certain mechanism or transition in our environment. To this end, the integrated system modeling of complex systems will form the basis of a comprehensive assessment of sustainability and can provide a clearer vision of the dynamics of the globe [59].

\subsubsection{Socio-Technical Systems}

A socio-technical system is a collection of stakeholders, their networks, practices, and knowledge; the technologies they use; their collective representations; and the standards and rules they adopt [30]. The broad range of sustainability transition literature addresses the long-term transformation of socio-technical systems into sustainable systems in various fields, such as renewable power [29,60,61], transportation [62], and agricultural and food systems $[30,39]$. In the SDGs, for instance, the energy system is represented mainly as a technological system rather than a complicated socio-technical one. Nevertheless, for the latter, improvements in consumer behavior or other behavioral changes tend to balance several of the modern technology's beneficial effects. In addition, socio-technical systems also have low- and no-tech responses to challenges [29].

\subsubsection{Complex Adaptive Systems}

Complex adaptive systems are systems whose behaviors emerge on different spatial and temporal scales as a result of non-linear interrelationships, among a large number of elements without central control [50]. Within a system and between a system and its environment, they contain several complex, interconnected components. They are open systems, which means that elements and systems have an effect on the system beyond the boundaries of the observed system and its influence, and vice versa. Rusoja et al. [33] conceptualized healthcare systems as a complex adaptive system which is a set of interacting entities that change quickly in relation to each other and their shared environment. The value of this approach is that complex adaptive systems necessarily reflect the evolving environment, its key actors and their connections in medical comprehension over time, helping planners to consider and optimize health outcomes more effectively. Jagustović et al. [50] discussed the contribution of systems thinking as a conceptual method and the characteristics of complex adaptive systems as a basis for supporting the scaling-up of sustainable agriculture.

\subsubsection{System of Systems}

A complex system of systems, ranging from individually unique non-physical influencers to a wider collection of social and environmental influencers who have a common 
effect on the larger society-environment-economy system, strongly influences human, ecological and economic outcomes. Via several layers of systems that interact in many ways, sustainability plays a major role [63]. At the micro-level, there are individual layer systems. At meso-level, there are various forms of infrastructure, such as production and transportation, power generation, wastewater treatment and control, etc. At macro-level, the infrastructure consists of interconnected networks, including the power grid and the oil and gas storage and networking. System of systems engineering is explicitly meant to address problems of this essence. It allows decision-makers to solve the challenges of creating a robust system of systems that tackles the measurement of sustainability performance [64].

System of systems engineering involves identifying interconnections between technology, management, environmental and social issues, finances, and corporate strategies. The system of systems architecture and the system life cycle approach are essential to addressing various requirements and planning for long-term sustainable operation and maintenance [65]. System of systems engineering promises a toolset that have been adapted to modelling, simulation, optimization, and decision analysis of complex systems with both quantitative and qualitative characteristics. To resolve the need for a straightforward description of the process to develop the required technical, financial, and managerial support modules, a system of systems hierarchy spanning social, economic, and operational levels can allow sustainable development and strategic planning [23].

\subsubsection{Cyber Physical Systems}

Cyber physical systems can be characterized as systems that interconnect physical and software components to generate large-scale effects, each functioning on different temporal and spatial scales, demonstrating multiple and distinct behavioral mechanisms, and communicating with each other in a variety of context-changing ways [66]. It is a revolutionary technology when combined in manufacturing, wherein knowledge is strictly managed and coordinated from all relevant perspectives between the physical assembly line and the cyber computational space [67]. A cyber physical system connects a layer of physical components, such as workstations, components, and equipment, with a cyber layer of information systems, through sensors and devices. In other words, the virtualization of the process is achieved by cyber-physical systems. To attain a sustainable community on a worldwide scale as soon as practicable, it will be vital to allow communication and cooperation, such as knowledge sharing, triggering actions, and autonomous control between humans, machines, and materials.

The Japanese Cabinet's 'Society 5.0' initiative aims to establish a sustainable society through a cyber-physical system for human security and well-being [68]. Via cyber-physical systems, it is possible to analyze and visualize various big data artifacts obtained from low-power intelligent sensor networks and kept in information cloud storage using highcomputing analytical tools in cyberspace. Such useful data, often difficult to notice for humans alone, can inform the actions taken by decision-makers to resolve social challenges and economic development in the physical realm.

\section{Discussion}

This paper presents the first scoping study on the crossovers and connectivity between systems engineering and the SDGs.

To do this, we adopted an innovative approach and integrated the emerging technique of NLP to the established SLR process. Consequently, we present a comprehensive analysis of the connectivity between systems engineering and the SDGs.

Our paper contributes a comprehensive and theoretically grounded picture of the crossovers and connectivity between systems engineering and the SDGs. This research provides a useful lens for analyzing the existing resolutions in moving towards more holistic, dynamic and integrated perspectives for sustainable development. Systems engineering practitioners and the sustainability research community can refer to this body of work 
when designing and improving the current implementation framework according to their value creation goals.

As with other studies, our review has the potential for bias. For instance, if the scoping review does not consider all available data, selection bias can occur. Our search query (as shown in Table 1) contains the key concepts within systems engineering domain. However, it is inevitable that papers that contain other systems engineering concepts (that are not considered in Table 1) cannot be retrieved from the search. As our study aims to ensure a broad coverage of literature related to systems engineering and sustainable development, we believe the design of the search terms is appropriate for this particular study.

Due to the large coverage of the search inherent in the method, scoping reviews take a considerable amount of time to finish. The number of studies included in the review process can be sizable by design. Thus, a large research team could enhance the screening of a greater number of studies and consider other references for potential inclusion in the scoping analysis.

This scoping study is not an end but a beginning which is intended to lead into further work. It has looked at a broad range of systems engineering core concepts for helping to achieve the SDGs but has not been able to consider each of the goals in details. This again highlights the gaps in current practices for using systems engineering core concepts to understand and explain the complexity behind sustainability. The need for examining existing frameworks and methods that can be used to assess this type of work is therefore urgent.

\section{Conclusions}

The present study was designed to analyze the existing literature that uses a systems engineering perspective to advance the SDGs. One of the significant findings to emerge from this study is that systems engineering has great potential to contribute to global sustainability. It offers various approaches and toolsets to enable the success of complex systems, drives the evolution of socio-technical systems, and assists decision-makers to implement the SDGs in an improved and traceable manner. Our investigation also determines the relationship between systems engineering and sustainable development and proposes interactions that may contribute to the achievement of the SDGs. It confirms that systems engineering has been recognized as an effective way to reframe the SDGs.

The insights gained from this study may be of assistance in creating a better understanding of the concept crossovers between systems engineering and sustainable development. It lays the groundwork for future research into the holism and dynamics of the SDGs and adds to the growing body of research that advocates using systems engineering methods to integrate sectoral efforts towards global sustainability. Systems engineering can act as a shared foundation for future research in harmonizing, optimizing and advancing the SDGs.

We hope that our findings, analysis, and discussion can pave the way for an appreciation of the value of systems engineering for the SDGs. We expect that future studies can take advantage of the crossovers between systems engineering and the SDGs to discover specific ways that systems engineering can contribute to a sustainable future.

Author Contributions: Data curation, L.Y.; Formal analysis, L.Y.; Investigation, L.Y.; Methodology, L.Y.; Supervision, K.C.; Visualization, L.Y.; Writing-original draft, L.Y. and K.C.; Writingreview and editing, L.Y. and K.C. All authors have read and agreed to the published version of the manuscript.

Funding: This research received no external funding.

Institutional Review Board Statement: Not applicable.

Informed Consent Statement: Not applicable.

Data Availability Statement: The data presented in this study are available on request from the corresponding author. 
Conflicts of Interest: The authors declare no conflict of interest.

\section{References}

1. Sachs, J.D.; Schmidt-Traub, G.; Mazzucato, M.; Messner, D.; Nakicenovic, N.; Rockström, J. Six Transformations to achieve the Sustainable Development Goals. Nat. Sustain. 2019, 2, 805-814. [CrossRef]

2. Jabareen, Y. A New Conceptual Framework for Sustainable Development. Environ. Dev. Sustain. 2008, 10, 179-192. [CrossRef]

3. United Nations. United Nations Millennium Declaration. In Proceedings of the Millennium Development Summit of the United Nations, New York, NY, USA, 6-8 September 2000.

4. United Nations. The future we want. In Proceedings of the United Nations Conference on Sustainable Development, Rio de Janeiro, Brazil, 20-22 June 2012.

5. United Nations. Transforming our World: The 2030 Agenda for Sustainable Development. In Proceedings of the United Nations Summit, New York, NY, USA, 25-27 September 2015.

6. Barbier, E.B.; Burgess, J.C. The Sustainable Development Goals and the systems approach to sustainability. Econ. Open Access Open Assess. E J. 2017. [CrossRef]

7. Le Blanc, D. Towards Integration at Last? The Sustainable Development Goals as a Network of Targets. Sustain. Dev. 2015, 23, 176-187. [CrossRef]

8. Scharlemann, J.P.W.; Brock, R.C.; Balfour, N.; Brown, C.; Burgess, N.D.; Guth, M.K.; Ingram, D.J.; Lane, R.; Martin, J.G.C.; Wicander, S.; et al. Towards understanding interactions between Sustainable Development Goals: The role of environment-human linkages. Sustain. Sci. 2020, 15, 1573-1584. [CrossRef]

9. Laurent, A.; Molin, C.; Owsianiak, M.; Fantke, P.; Dewulf, W.; Herrmann, C.; Kara, S.; Hauschild, M. The role of life cycle engineering (LCE) in meeting the sustainable development goals-Report from a consultation of LCE experts. J. Clean. Prod. 2019, 230, 378-382. [CrossRef]

10. Selomane, O.; Reyers, B.; Biggs, R.; Hamann, M. Harnessing Insights from Social-Ecological Systems Research for Monitoring Sustainable Development. Sustainability 2019, 11, 1190. [CrossRef]

11. Iandolo, F.; Barile, S.; Armenia, S.; Carrubbo, L. A system dynamics perspective on a viable systems approach definition for sustainable value. Sustain. Sci. 2018, 13, 1245-1263. [CrossRef]

12. Diwekar, U. Perspective on pursuit of sustainability: Challenges for engineering community. Clean Technol. Environ. Policy 2015, 17, 1729-1741. [CrossRef]

13. Hillary, S.; James, M.; Dorothy, M.; Regina, G.; Dov, D.; Daniel, K.; Patrick, G.; Eileen, A.; Scott, J. Systems Engineering and System Definitions. Available online: https://www.incose.org/docs/default-source/default-document-library/final_-se-definition. pdf?sfvrsn=340b9fc6_0 (accessed on 19 February 2021).

14. Pearce, O.J.D.; Murry, N.J.A.; Broyd, T.W. Halstar: Systems engineering for sustainable development. Proc. Inst. Civ. Eng. Eng. Sustain. 2012, 165, 129-140. [CrossRef]

15. Colquhoun, H.L.; Levac, D.; O’Brien, K.K.; Straus, S.; Tricco, A.C.; Perrier, L.; Kastner, M.; Moher, D. Scoping reviews: Time for clarity in definition, methods, and reporting. J. Clin. Epidemiol. 2014, 67, 1291-1294. [CrossRef] [PubMed]

16. Peters, M.D.J.; Godfrey, C.M.; Khalil, H.; McInerney, P.; Parker, D.; Soares, C.B. Guidance for conducting systematic scoping reviews. Int. J. Evid. Based. Healthc. 2015, 13, 141-146. [CrossRef]

17. Levac, D.; Colquhoun, H.; O’Brien, K.K. Scoping studies: Advancing the methodology. Implement. Sci. 2010, 5, 69. [CrossRef] [PubMed]

18. Arksey, H.; O'Malley, L. Scoping studies: Towards a methodological framework. Int. J. Soc. Res. Methodol. 2005, 8, 19-32. [CrossRef]

19. Bird, S.; Klein, E.; Loper, E. Natural Language Processing with Python: Analyzing Text with the Natural Language Toolkit; O'Reilly Media, Inc.: Sebastopol, CA, USA, 2009; ISBN 0596555717.

20. Pickering, C.; Byrne, J. The benefits of publishing systematic quantitative literature reviews for PhD candidates and other early-career researchers. High. Educ. Res. Dev. 2014, 33, 534-548. [CrossRef]

21. Deshpande, P.C.; Aspen, D.M. A Framework to Conceptualize Sustainable Development Goals for Fishing Gear Resource Management. In Handbook of Sustainability Science and Research; Leal Filho, W., Ed.; Springer: Cham, Switzerland, 2018; pp. 727-744.

22. Sage, A.P. Systems engineering and management for industrial ecology and sustainable development. In Proceedings of the 1997 IEEE International Conference on Systems, Man, and Cybernetics. Computational Cybernetics and Simulation, Orlando, FL, USA, 12-15 October 1997; Volume 1, pp. 784-790.

23. Anderson, A.; Suryanarayanan, S. An Enterprise Systems Engineering Approach to Electrification: Looking at the Bigger Picture Through Life-Cycle Analysis of Community Microgrids: A Case Study in Papua New Guinea. IEEE Electrif. Mag. 2018, 6, 18-31. [CrossRef]

24. Bertheau, P.; Hoffmann, M.M.; Eras-Almeida, A.; Blechinger, P. Assessment of Microgrid Potential in Southeast Asia Based on the Application of Geospatial and Microgrid Simulation and Planning Tools. In Sustainable Energy Solutions for Remote Areas in the Tropics; Gandhi, O., Srinivasan, D., Eds.; Springer: Cham, Switzerland, 2020; pp. 149-178.

25. Machado, P.G.; Mouette, D.; Rathmann, R.; dos Santos, E.; Peyerl, D. Is Energy Planning Moving Towards Sustainable Development? A Review of Energy Systems Modeling and Their Focus on Sustainability. In International Business, Trade and Institutional Sustainability; Springer International Publishing: New Year, NY, USA, 2020; pp. 629-644. 
26. Rauner, S.; Budzinski, M. Holistic energy system modeling combining multi-objective optimization and life cycle assessment. Environ. Res. Lett. 2017, 12, 124005. [CrossRef]

27. Reid, J.; Zeng, C.; Wood, D. Combining Social, Environmental and Design Models to Support the Sustainable Development Goals. In Proceedings of the 2019 IEEE Aerospace Conference, Big Sky, MT, USA, 2-9 March 2019; pp. 1-13.

28. Schot, J.; Steinmueller, W.E. Three frames for innovation policy: R\&D, systems of innovation and transformative change. Res. Policy 2018, 47, 1554-1567. [CrossRef]

29. Hillerbrand, R. Why Affordable Clean Energy Is Not Enough. A Capability Perspective on the Sustainable Development Goals. Sustainability 2018, 10, 2485. [CrossRef]

30. Serhan, H.; Yannou-Lebris, G. The engineering of food with sustainable development goals:policies, curriculums, business models, and practices. Int. J. Sustain. Eng. 2020, 1-14. [CrossRef]

31. Palmer, E.; Burton, R.; Haskins, C. A Systems Engineering Framework for Bioeconomic Transitions in a Sustainable Development Goal Context. Sustainability 2020, 12, 6650. [CrossRef]

32. Tan, D.T.; Siri, J.G.; Gong, Y.; Ong, B.; Lim, S.C.; MacGillivray, B.H.; Marsden, T. Systems approaches for localising the SDGs: Co-production of place-based case studies. Global. Health 2019, 15, 85. [CrossRef] [PubMed]

33. Rusoja, E.; Haynie, D.; Sievers, J.; Mustafee, N.; Nelson, F.; Reynolds, M.; Sarriot, E.; Swanson, R.C.; Williams, B. Thinking about complexity in health: A systematic review of the key systems thinking and complexity ideas in health. J. Eval. Clin. Pract. 2018, 24, 600-606. [CrossRef] [PubMed]

34. Michalopoulou, E.; Shallcross, D.E.; Atkins, E.; Tierney, A.; Norman, N.C.; Preist, C.; O’Doherty, S.; Saunders, R.; Birkett, A.; Willmore, C.; et al. The End of Simple Problems: Repositioning Chemistry in Higher Education and Society Using a Systems Thinking Approach and the United Nations' Sustainable Development Goals as a Framework. J. Chem. Educ. 2019, 96, $2825-2835$. [CrossRef]

35. MacLachlan, M.; McVeigh, J.; Cooke, M.; Ferri, D.; Holloway, C.; Austin, V.; Javadi, D. Intersections Between Systems Thinking and Market Shaping for Assistive Technology: The SMART (Systems-Market for Assistive and Related Technologies) Thinking Matrix. Int. J. Environ. Res. Public Health 2018, 15, 2627. [CrossRef]

36. Stead, S.M. Using systems thinking and open innovation to strengthen aquaculture policy for the United Nations Sustainable Development Goals. J. Fish Biol. 2019. [CrossRef] [PubMed]

37. Zhang, Q.; Prouty, C.; Zimmerman, J.B.; Mihelcic, J.R. More than Target 6.3: A Systems Approach to Rethinking Sustainable Development Goals in a Resource-Scarce World. Engineering 2016, 2, 481-489. [CrossRef]

38. Allen, C.; Metternicht, G.; Wiedmann, T. Initial progress in implementing the Sustainable Development Goals (SDGs): A review of evidence from countries. Sustain. Sci. 2018, 13, 1453-1467. [CrossRef]

39. Whitfield, S.; Challinor, A.J.; Rees, R.M. Frontiers in Climate Smart Food Systems: Outlining the Research Space. Front. Sustain. Food Syst. 2018, 2. [CrossRef]

40. Hurst, G.A. Systems thinking approaches for international green chemistry education. Curr. Opin. Green Sustain. Chem. 2020, 21, 93-97. [CrossRef]

41. Pant, A.; Kumar, S. Climate Change, Public Health and Implementation of Sustainable Development Goals in India-Issues and Challenges. Indian J. Public Heal. Res. Dev. 2019, 10, 60. [CrossRef]

42. Morton, S.; Pencheon, D.; Bickler, G. The sustainable development goals provide an important framework for addressing dangerous climate change and achieving wider public health benefits. Public Health 2019, 174, 65-68. [CrossRef]

43. Kutty, A.A.; Abdella, G.M.; Kucukvar, M.; Onat, N.C.; Bulu, M. A system thinking approach for harmonizing smart and sustainable city initiatives with United Nations sustainable development goals. Sustain. Dev. 2020, 28, 1347-1365. [CrossRef]

44. Reynolds, M.; Blackmore, C.; Ison, R.; Shah, R.; Wedlock, E. The Role of Systems Thinking in the Practice of Implementing Sustainable Development Goals. In Handbook of Sustainability Science and Research; Leal Filho, W., Ed.; Springer: Cham, Switzerland, 2018; pp. 677-698.

45. Petillion, R.J.; Freeman, T.K.; McNeil, W.S. United Nations Sustainable Development Goals as a Thematic Framework for an Introductory Chemistry Curriculum. J. Chem. Educ. 2019, 96, 2845-2851. [CrossRef]

46. Duboz, R.; Echaubard, P.; Promburom, P.; Kilvington, M.; Ross, H.; Allen, W.; Ward, J.; Deffuant, G.; de Garine-Wichatitsky, M.; Binot, A. Systems Thinking in Practice: Participatory Modeling as a Foundation for Integrated Approaches to Health. Front. Vet. Sci. 2018, 5. [CrossRef] [PubMed]

47. Zelinka, D.; Amadei, B. A methodology to model the integrated nature of the Sustainable development goals: Importance for engineering education. In Proceedings of the ASEE Annual Conference and Exposition, Columbus, OH, USA, $25-28$ June 2017.

48. Eustachio, J.H.P.P.; Caldana, A.C.F.; Liboni, L.B.; Martinelli, D.P. Systemic indicator of sustainable development: Proposal and application of a framework. J. Clean. Prod. 2019, 241, 118383. [CrossRef]

49. Kioupi, V.; Voulvoulis, N. Education for Sustainable Development: A Systemic Framework for Connecting the SDGs to Educational Outcomes. Sustainability 2019, 11, 6104. [CrossRef]

50. Jagustović, R.; Zougmoré, R.B.; Kessler, A.; Ritsema, C.J.; Keesstra, S.; Reynolds, M. Contribution of systems thinking and complex adaptive system attributes to sustainable food production: Example from a climate-smart village. Agric. Syst. 2019, 171, 65-75. [CrossRef]

51. Keesstra, S.; Mol, G.; de Leeuw, J.; Okx, J.; Molenaar, C.; de Cleen, M.; Visser, S. Soil-Related Sustainable Development Goals: Four Concepts to Make Land Degradation Neutrality and Restoration Work. Land 2018, 7, 133. [CrossRef] 
52. Von Bertalanffy, L. General theory of systems: Application to psychology. Soc. Sci. Inf. 1967, 6, 125-136. [CrossRef]

53. Fucà, R.; Cubico, S.; Favretto, G.; Leitão, J. The "Local Town Market Area" in Enna, Sicily: Using the Psychology of Sustainability to Propose Sustainable and Developmental Policies. Sustainability 2019, 11, 486. [CrossRef]

54. Wilcox, B.A.; Aguirre, A.A.; De Paula, N.; Siriaroonrat, B.; Echaubard, P. Operationalizing One Health Employing Social-Ecological Systems Theory: Lessons From the Greater Mekong Sub-region. Front. Public Health 2019, 7. [CrossRef]

55. Donaires, O.S.; Cezarino, L.O.; Caldana, A.C.F.; Liboni, L. Sustainable development goals-An analysis of outcomes. Kybernetes 2019, 48, 183-207. [CrossRef]

56. Wieser, A.A.; Scherz, M.; Maier, S.; Passer, A.; Kreiner, H. Implementation of Sustainable Development Goals in construction industry-A systemic consideration of synergies and trade-offs. IOP Conf. Ser. Earth Environ. Sci. 2019, 323, 012177. [CrossRef]

57. Obersteiner, M.; Rydzak, F.; Fritz, S.; McCallum, I. Valuing the Potential Impacts of GEOSS: A Systems Dynamics Approach. In The Value of Information; Laxminarayan, R., Macauley, M., Eds.; Springer: Dordrecht, The Netherlands, 2012; pp. 67-90.

58. Allen, C.; Metternicht, G.; Wiedmann, T. Prioritising SDG targets: Assessing baselines, gaps and interlinkages. Sustain. Sci. 2019, 14, 421-438. [CrossRef]

59. Schaubroeck, T.; Rugani, B. A Revision of What Life Cycle Sustainability Assessment Should Entail: Towards Modeling the Net Impact on Human Well-Being. J. Ind. Ecol. 2017, 21, 1464-1477. [CrossRef]

60. Renouf, M.A.; Kenway, S.J. Evaluation Approaches for Advancing Urban Water Goals. J. Ind. Ecol. 2017, 21, 995-1009. [CrossRef]

61. Ahmad, N.; Derrible, S. Evolution of Public Supply Water Withdrawal in the USA: A Network Approach. J. Ind. Ecol. 2015, 19, 321-330. [CrossRef]

62. Liu, G.; Zhai, R. Application and Development of Systems Engineering in Road Traffic Management. In Proceedings of the International Conference on Transportation and Development 2018; Wang, Y., McNerney, M.T., Eds.; American Society of Civil Engineers: Reston, VA, USA, 2018; pp. 306-313.

63. Muller, G.; Elvebakk, L.; van der Velde, J.; Lean, F. Mac Roadmapping for Sustainability; How to Navigate a Social, Political, and Many Systems-of-Systems Playing Field? A Local Initiative. In Proceedings of the 2019 14th Annual Conference System of Systems Engineering (SoSE), Anchorage, AK, USA, 19-22 May 2019; pp. 317-322.

64. Searcy, C. Corporate sustainability performance measurement: Lessons from system of systems engineering. In Proceedings of the 2009 IEEE International Conference on Systems, Man and Cybernetics, San Antonio, TX, USA, 11-14 October 2009; pp. 1057-1060.

65. Nativi, S.; Santoro, M.; Giuliani, G.; Mazzetti, P. Towards a knowledge base to support global change policy goals. Int. J. Digit. Earth 2020, 13, 188-216. [CrossRef]

66. Oláh, J.; Aburumman, N.; Popp, J.; Khan, M.A.; Haddad, H.; Kitukutha, N. Impact of Industry 4.0 on Environmental Sustainability. Sustainability 2020, 12, 4674. [CrossRef]

67. Bonilla, S.; Silva, H.; Terra da Silva, M.; Franco Gonçalves, R.; Sacomano, J. Industry 4.0 and Sustainability Implications: A Scenario-Based Analysis of the Impacts and Challenges. Sustainability 2018, 10, 3740. [CrossRef]

68. Shiroishi, Y.; Uchiyama, K.; Suzuki, N. Society 5.0: For Human Security and Well-Being. Computer 2018, 51, 91-95. [CrossRef] 